\title{
The Narrative Economy of Social Media: Mobilising Farming Economies, Identities and Relations
}

ADELE MILLARD, The University of Western Australia

\begin{abstract}
This paper looks at social media as new fields through which Western Australian farmers of black truffles negotiate potentially global consumer markets. The author argues that the analytical concept of narrative economy deserves greater exploration in social theories on market relations through changing mediascapes. Some farmers embrace social media as influential, though problematic, marketing forums while others refuse to engage. What ensues are shifting distributions of economic, social, cultural, and symbolic capital as truffle farmers who use social media have strategic development advantages over those who do not.
\end{abstract}

\section{KEYWORDS}

Capital; Farmers; Narrative Economy; Social Media; 


\section{Introduction}

We have all seen how the rise of popular television shows such as MasterChef, Iron Chef and The Great British Bake Off have manifestly leveraged professional chefs and talented home cooks into the celebrity spotlight over the past 10 years. So it is not surprising that there has been considerable scholarly research into the way that media representations of food inform, and are informed by, people's food consumption practices (De Solier 2013; Phillipov 2012; Lewis 2011; Modesto, Savage \& Warde 2006). This paper turns the gaze in the other direction, and looks at the changing relationships between media and the farmers who produce food. Specifically, it looks at social media as forums through which Western Australian farmers of black truffle (Tuber melanosporum) are transforming the economic, social and political order of their home communities. Farm websites, blogs and interactive webpages facilitate communication directly between farmers and consumers. Social media provide valuable platforms through which farmers, marketing professionals, appreciative consumers and internet 'trolls' give and receive information and opinions on all matters relating to truffles. The author proposes that social media provides a broad field in which the concept of 'the narrative economy' can be studied as an emerging phenomenon in Australian farming practice. Ultimately, this paper argues that the analytical concept of narrative economy deserves greater deconstruction, development and exploration in social theories on mediated intimacies in capitalist market culture.

\section{Grounding Theory: The Social and Economic Context}

Black truffles do not occur naturally in Western Australia. They are of French biomorphological origin, and cultivated on the roots of hazelnut and oak trees on trufferies (truffle plantations). Truffles are notable for many reasons including their expense and their aroma. The fungi's strong smell stimulates olfactory nerves in humans (and other animals), producing physical sensations of taste. Generally speaking, people either love or hate truffles - such is their pungency. But with global retail prices in the vicinity of $£ 1,250$ per kilo, a farmer of black truffles could be expected to love them.

The first Western Australian trufferie was established in 1997; and the first mature truffle was harvested from that property on 28 July 2003 (Nic Malajczuk, pers. comm.). Production has escalated since then with roughly 6500 kilograms harvested from 50 Western Australian trufferies in 2014 (Truffle Producers of Western Australia, pers. comm.). In fiscal terms, that is about $£ 8$ million. The median size of Western Australian trufferies is 760 trees, although the range spans from 10 to 38,000 trees (Mathews 2014). The Western Australian truffle industry is very proud of itself indeed!

Western Australian farmers historically have not commercially engaged directly with agrifood consumers. Farmers sold their produce to industry-wide representative bodies, who marketed and distributed farmers' produce in bulk to wholesalers locally and globally. The commencement of black truffle cultivation in the state's southwest coincided with the rise, and convergence, of food and social media in popular culture in Australia and abroad. Facebook was launched in February 2004 (Boyd \& Ellison 2007), within one year of the first Western Australian truffle harvest; and the television series MasterChef, which was founded in the United Kingdom in 1990, had become a global franchise including Australia by 2009 (Lewis 2011). One of many trends that arose from the popularisation of food practices included an increased demand on farmers for direct engagement with consumers, who sought more information about how, and by whom, their foodstuffs were produced. Social media facilitated that engagement. 
The capacity of social media to host geographically far-reaching communication is significant for Western Australian truffle farmers, whose rapidly perishable fungi must be consumed within one week of harvest to maintain quality (Mathews 2013; Truffle Producers of Western Australia 2014). Farmers use social media to attract new consumers to their trade networks, and to maintain networks with existing clients - ensuring truffles have predetermined destinations before they are harvested. Vast, sparsely-populated deserts and semiarid zones separate the truffle-growing region, in the state's southwest, from the rest of the continent; and even vaster oceans separate it from markets abroad. Considerable local status and influence are accorded to farmers who attract global trade to this relatively isolated region. That they can draw money, endorsement from celebrated chefs, and tourists to their locale alters not only the regional economy, but also the visible and existential social milieu.

\section{Theoretical Background}

Consumers are accorded minimal power in anthropologist Arjun Appadurai's (1990) notion of 'mediascapes'. Appadurai $(1990,307)$ says that, when mediascapes converge with 'financescapes' in the form of advertising media, 'the consumer is consistently helped to believe that he or she is an actor, where in fact he or she is at best a chooser'. Media types, functions, and accessibilities have changed in the 25 years since Appadurai advanced his theory. Social media, which did not exist in 1990, facilitate intimate and public spaces through which consumers can negotiate, and contest, market narratives in direct engagement with producers and other consumers (Couldry 2015; De Andrade e Silva 2014; Van Dijck 2013). This paper argues that consumers of truffles may be recipients of the industry's online marketing narratives but social media facilitates consumer engagement with farmers in narrative exchange. As such, consumers are perceived by truffle growers as being active constructors of narratives who have the power to influence other consumers' perceptions.

The concept of 'narrative economy' tends to be used in social theory to infer that stories are constructed to add value and meaning to certain agenda (see Brandão \& Sousa 2015, 161; Hoxter 2011, 17; Hoskins 2010, 261; Morley 2006, 28; Scott 2004, 123-124). However, the term is never really unpacked to consider the multiple ways narratives might be negotiated and reconstructed through processes of exchange. This paper expands the term to accommodate the ways farmers and consumers actively negotiate values ascribed to truffles, and related social actors, through narratives exchange in social media domains. Western Australian truffle farmers see consumers as agents whose contributions to online market narratives can add, or undermine, values ascribed to the industry's discursive forms of 'capital' (Bourdieu 2002). Therefore, I argue that the narrative economy of Western Australian truffle markets can be seen as the negotiation of stories that are constructed and ascribed values and meanings, by social actors, in relation to tangible assets which can be exchanged for other forms of capital - such as money or power.

Access to capital is at the core of actors' agenda as they negotiate their places, and those of others, in the narrative economy. Anthropologist Pierre Bourdieu $(2007,101)$ argues that people negotiate their positions within 'fields' through the acquisition, negotiation, exchange and withholding of capital, depending on what they already have and relative to what they would like to have. In the context of this paper, the fields are social media. The narrative economy is the analytical concept referring to the ways values attributable to capital are negotiated through the field. Bourdieu $(2007,101)$ says fields are 'various, relatively autonomous, social spaces' in which competition centres on the acquisition of economic, social, cultural and symbolic capital. For example, actors may want to display social capital (educational qualifications) in order to acquire more economic capital (cultural goods, such 
as money). Or they may want to withhold social capital in the form of valuable information to prevent it from becoming common knowledge (and therefore losing their ability to attract economic capital in return for the specialist knowledge in a niche market). For Bourdieu (2002, 282), cultural capital has three forms: it can be 'objectified', including cultural goods, like truffles; 'embodied', such as a person's accent; or an 'institutional state', such as academic knowledge. All three forms may serve as symbolic capital, indicating the status of one person in relation to others (such as class).

Bourdieu $(2002,285)$ does not see a person's access to cultural capital as fixed, but rather as informing, and informed by their place in relation to social and economic capital. Cultural capital, including its symbolic incarnations, can be used to leverage greater access to social and economic power; and it can also be lost or contribute to the loss of one's social and economic power. Forthcoming case studies show that farmers who have cultural capital in the form of communication skills may leverage greater access to economic, social and symbolic capital than their peers.

Media academic José van Dijck (2013) suggests social actors are under pressure to use the internet in ways that sustain economic, social, and symbolic power. Van Dijck says:

The culture of connectivity ... is staked on neoliberal economic principles. Connectivity derives from a continuous pressure - both from peers and from technologies - to expand through competition and gain power through strategic alliances (Van Dijck 2013, 20-21).

In reviewing Van Dijck (2013), James Carviou (2014, 260) calls for greater examination of social media sites in fostering and maintaining identity development and sustainability. Western Australian truffle growers serve as useful cases to address Carviou's (2014) query because they are leading growing trends among farmers to advance and sustain brand identities through social media. This is a new frontier for the political economy of farming. It is also a new frontier for communities whose dominant industry is agriculture, and whose social organisation is reconfigured around members who attract economic, social, cultural and symbolic capital to their locales. Social media is a means of expanding individual, community and industrial profiles.

This paper takes up Van Dijck's (2013) argument and applies it to the narrative economy of Western Australian truffle markets, converging with an updated conceptualisation of Appadurai's (1990) notion of mediascapes, and Bourdieu's (YEAR) constructions of capital. It argues that market pressure to engage in narrative exchange with consumers through social media, and to do so well, informs change in the distribution of economic, social and symbolic capital among farmers. Consumers who engage with farmers through social media inform the capital values attributed to those farmers, their truffles, and their producer-locales in broader fields - such as commercial markets and in their home communities.

An important feature of Van Dijck's writing is her reluctance to use the term 'social media' because 'the space of 'the social' on this reading, is a playground for deep economic battles about new forms of value' (Couldry 2015, 641). Her concern about using the term, social media, is shared by media studies academic Nick Couldry who writes:

'Research into social media must be conducted with caution, because on social media platforms it is the very possibility of an "us" ... that is being produced for motives that simulate a certain politics, yet remain fundamentally commercial' (Couldry 2015, 643). 
Despite his argument that social media facilitate the advancement of political economic agenda, Couldry $(2015,637)$ acknowledges that 'institutions something like social media platforms can play a part in a more democratic future' (original emphasis). This paper builds on Couldry's suggestion, explaining how administrators of an emergent regional brand are beginning to use social media to democratise the distribution of capital among truffle farmers.

\section{Methodology}

This paper arises out of anthropological doctoral studies into the narrative economy of Western Australian truffle markets between 2008 and 2014. Participant observation fieldwork involved working alongside 29 truffle growers to observe and query their daily practices, as well as recording semi-structured interviews, and studying market engagement types including print and broadcast media, face-to-face trade, and ritualistic performances (such as degustation dinners and harvest festivals). Social media emerged unexpectedly, for farmers and the researcher, in the first year of fieldwork as a space in which farmers directly engaged with consumers. It was duly added to the taxonomy of engagement types. Data gathering included monitoring farmers' social media usage, including public and private (direct messaging) communication with consumers.

Three case studies have been chosen to represent farmers' social media engagement types in this paper: absolute engagement, partial engagement, and non-engagement. The first is a lucrative truffle growing cooperative that invests substantial economic, social and cultural capital into developing a widespread online presence. The second case study is an owneroperator truffle farmer who has a measured approach to social media - balancing online engagement with his personal limitations of time, skill, and economic resources. And the third example is a farmer who refuses to engage with consumers through social media. The paper closes with an important post-script, showing how regional brands may use social media to influence more democratic access to capital among growers. While the regional brand represented here developed late in the fieldwork period, its administrators and marketing professionals were quick to use social media to develop the collective capital of local agri-food producers. This development is included to illustrate further the complexity of market relations negotiated through social media, and that even technological 'laggards' (Rogers 2003) need not be 'victims' (Klein 2004) as capital is contested in the narrative economy.

\section{Case Study 1: Media Domination - The Rise of the Oligarchs}

The first truffle farm was established in 1997, when the World Wide Web was still in its infancy and certainly not in as common and varied daily use as it is today (World Wide Web Foundation 2015). The mycorrhizal scientist who developed the truffle farm went doorknocking to raise capital from investors who could bankroll the venture. Those investors comprised people who had existing involvement in the food industry - including farmers, viticulturists, restauranteurs and chefs. They each could add value to the trufferie, not only in terms of finance but also by wayof developing markets through their existing professional networks. Within a year of the first truffle harvest in 2003, Facebook was launched (boyd et al. 2007). The synchronicity could hardly have been better timed. Once the cooperative knew that the truffle trial had succeeded, it employed professional management and marketing staff to take the investment further into consumer domains. 
One marketer in particular, Ben, had spent many years living in northern Italy - another region historically associated with truffles. He had worked there in both professional photography and public relations. Ben drew on his communications know-how to reach out to local and global markets. As production was already predicted to exceed existing demand, Ben also had the task of educating international truffle markets that Western Australia was a source of fresh black truffles outside of the northern hemisphere season (which falls in late autumn to early winter). Furthermore, he was charged with educating the local general public about what truffles were, and how their very values, meanings and points-of-difference had been constructed as objects of desire in French and Italian culinary traditions. One of the first things Ben did for the cooperative was to develop online media presence through Facebook and YouTube. He was one of Western Australia's first online marketers of agri-food produce from a farm.

Online marketing involved more complex dynamics than the forms of media with which Ben had worked previously. It not only provided a means through which Ben could deliver narratives directly to a potentially infinite market. Social media platforms also enabled anyone with access, know-how and inclination to construct narratives of their own in response to Ben's publicity campaign - positive or otherwise. As a case in point, the trufferie manager's opera singer daughter had delighted diners at a degustation function in 2008 when she and three classical string musicians performed The Truffle Song from Johann Strauss's operetta The Queen's Lace Handkerchief (see White, Smith \& Co. 2013). Given how well it was received by the dining patrons, Ben uploaded digital audio-visual footage of the performance to YouTube. The unadulterated vitriolic response from musical purists in the online comments was devastating for the singer. Rather than adding value to the narrative economy of truffles, it had simply negated value ascribed to the performer. The footage was ultimately removed from YouTube, as were any hyperlinks to the footage from the company's website.

At the same time as the cooperative was developing its trufferie, so too were some individual investors from within that cooperative developing their own truffle farms. Having learnt how to cultivate truffles and market them online, the shareholders who branched out on their own became competitors to, as well as members of, that cooperative. Cracks started to appear in the young industry. For about three years, which seemed like a lifetime to those tentatively trying to mobilise the industry as a strong and permanent feature of the Western Australian agricultural landscape, the market was dominated by three truffle growers - the cooperative and two of its now-former members.

The new oligopoly of truffle farmers had observed Ben's experiences, and they had seen the potential benefits and risks of social media as influential conduits for their own farming narratives. Each prioritised the development of an online presence - employing professional website builders to develop social media through which they could interact with potential consumers, including online order forms, question and answer facilities, and feedback forms. The farmers themselves developed social media accounts including Facebook and YouTube. Having seen Ben's experience of triggering online criticism through social media, they were made particularly aware of the need to limit public comments on their websites. They wanted narratives on their websites to uphold the aspirations they held for their produce. Each of these oligarchs used social media to assert the significance of their own respective roles in the innovation of the Western Australian truffle industry; and by inference, omission and sometimes overt expression, they also negated the status of their rivals. 


\section{Case Study 2: Keeping It Simple - The Lone Marketeer}

Rohan is a Perth-based owner of a rural property in the heart of Western Australia's truffle growing region. His professional background in African tourism has prepared Rohan well for engaging with people from all walks of life. It has also prepared him for attracting people to engage in business relationships despite separation by vast geographical distances. Rohan's property is a former orchard on which he built an architect-designed, luxury holiday lodge accommodating up to 12 guests at any one time. The business already had a website before the trufferie was established; and it received international endorsement through the high-end hotel guide $M r \& M r s$ Smith in 2008. Rohan established the trufferie as a sideline to his accommodation business. He felt that a trufferie could add financial and aesthetic value to the property.

Rohan was quick to recognise that in order to capitalise on his trufferie's production success, he would have to find buyers. The established oligarchs had cornered obvious local markets and he had no desire to embroil himself in, or contribute to, the sometimes bitter turf wars by poaching their clients. Rohan had been quietly networking among his international contacts through online media in the years building up to his first harvest in 2011. Building on networks from his work and travels through Africa, Europe and East Asia, Rohan at first notified people that he had planted inoculated trees. He maintained communication with these people through his property's website, email and Facebook. Consequently, Rohan's entire first truffle harvest was exported to those markets that he had developed and maintained online.

It is with trepidation that Rohan has ventured into other social media platforms beyond Facebook - such as YouTube, Twitter and Pinterest. For Rohan, the key is not to spread oneself too thin between tasks. Rohan has a young family in Perth who like to have their husband and father around. To this end, Rohan employs staff to undertake the day-to-day running of the property. He attends when there are guests in residence, and during peak times in the truffle season. Rohan maintains a constant and careful presence through social media just enough to cultivate new markets and sustain existing ones. He does not want to develop so many domains of online exchange that they all become too difficult to maintain, given his other work and family commitments. Professionalism and attention-to-detail are important for Rohan. If any single media platform was to be neglected, and consumer relations therein neglected, Rohan would consider this to be a failing on his part to maintain his own high standards. For Rohan, the decision not to engage with social media can sometimes mitigate the opportunity costs of engagement. This means that trying to engage with potential consumers across more social media platforms than he can maintain may cause damage to his reputation and, potentially, to trade relationships. Social media is important to Rohan's business; and he regards its potential to add or negate value to his business with respect.

\section{Case Study 3: Refusing Media Engagement - The Staunch Traditionalist}

Just as some farmers aspire to change the ways they engage with end-consumers, in order to effect changes in their social, economic and cultural lives, so too do others resist that change. The third example is Mike - a truffle farmer who has no interest in engaging in truffle marketing. He just wants to grow truffles, and sell them to someone else who can worry about distribution and retail. This is the form of trade relationship he has established over 30 years for his apples, pears and cherries; and he has no desire to expand his job description to include web designer, marketer, distributor, retailer or public relations specialist - skills that he associates with marketing through social media. 
Mike was born into the fourth generation of a large and successful farming family in the southwest. His family's surname features in state history archives, street names, plaques, and honour rolls, reflecting their historical wealth, social prominence, and political influence. But in the mid-to-late 1990s, significant economic downturns changed the family's fortune in the region. The local potato chip manufacturer shut down, and Australia's pork and dairy industries were deregulated (allowing cheap imports from overseas). Mike's family had been dependent on all of these sectors, in addition to their horticultural interests. While searching for alternatives, Mike heard about the truffle trials being undertaken and planted his first inoculated trees in 2007. He began harvesting his first truffles in 2012. As a diversifying horticulturalist, Mike is involved in planting, pruning, maintaining and harvesting of multiple fruit, vegetable and nut crops throughout the year. He is extraordinarily busy and relies on the occasional assistance of his brothers to meet harvest deadlines.

As stretched as Mike is, he has no time to learn divergently new skills such as webpage design, social media development, marketing, on-line retail, or global freight distribution. Given Mike's recent economic descent, nor does he have the means to employ someone to design and maintain a webpage for him. He grows his truffles, and he sells them to a neighbour who on-sells Mike's truffles to his own end-users. This neighbour is more than happy to maintain an online marketing presence - through both webpage and social media and to be publically and primarily identifiable as a truffle farmer. But in choosing not to engage with social media, Mike is diminishing his potential to capitalise economically, socially and politically at local and global levels in other ways too. Mike's stories, and those of his truffles, are missing from the narrative economy of Western Australian truffle markets as it is negotiated through the social media, potentially globally. Even if Mike's truffles are being sold internationally, it is the neighbour to whom Mike sells his truffles (and who does maintain an online presence), who takes the credit for that produce. It is the neighbour who is seen to attract money to the region and who therefore rises in prominence in the narrative economy of truffles.

\section{An Ethnographic Postscript: Regional Branding to the Rescue}

The Southern Forests Foods Council (SFFC) was formed to oversee the development of all existing, and future, agri-food markets in the region. The council was made up of representatives from industry and government, including marketing and strategic development professionals. The SFFC has developed the 'Genuinely Southern Forests' brand to promote food and food tourism from the region (Southern Forests Food Council 2014). Social media has played a critical role in the deployment of the regional brand to develop new markets and enhance existing ones; and the SFFC has played a vital role in uniting previously divided truffle farmers not only among themselves, but in association with other local food industries, to maximise potential synergies.

Initially, it was the truffle industry that dominated the SFFC's online narratives - such was the significance of its global profile in the food sector. Already well-known truffle growers featured front and centre of the SFFC's website, and local truffle stories dominated their online narratives. Symbolic of this somewhat imbalanced relationship is the name of the region's signature annual harvest festival the 'Truffle Kerfuffle: Southern Forests Food Festival'. Truffles receive top billing; and other foods cling on for leverage. However, over time, the SFFC's narratives have matured to reflect the interdependence of the region's many and varied food industries as one whole. Similarly, the SFFC originally used social media as one forum through which it tried to promote unity among all farmers, including truffle farmers as a notably fractured group. Now, social media not only serves a function as uniting 
farmers at superficial level, but also engages them in intra- and inter-industry narratives that affect that region as a whole. Consumers and farmers are kept informed on a plethora of relevant information largely through social media including: a website that provides feedback forms and contact details for SFFC staff members; email newsletters, which detail upcoming social and industry events that SFFC members can participate in - such as lessons in online marketing; and social media such as Facebook, Twitter, Google Plus, and Pinterest.

Those farmers who developed social media presence continue to do so, but they are no longer the only ones who can be identified and approached by potential consumers online. Even Mike features in truffle farming pictorial images on the SFFC's website and social media accounts - a point about which he expresses amusement, bemusement and pride. He does not engage with the SFFC through social media, but he sometimes attends meetings, classes and social events that he learns about through the SFFC's email newsletters. Also developing from the collaborations formed through the SFFC has been the Truffle Producers Association of Western Australia. This is a strictly local intra-industry organisation whose only online presence is maintained through email newsletters and a website featuring truffle news items from around the world, and biographies of local truffle growers. Relations within the Western Australia truffle industry are the best they have been for about five years.

\section{Analysis: Understanding the Narrative Economy}

Social media can be seen as providing spaces for new forms of market engagement between farmers and consumers. Mediated intimacies between farmers and consumers are mobile and discursive, challenging social theorists to explain shifting relations of power and capital. This paper argues that the existing analytical concept of narrative economy can inform, and be informed by, the use of social media by industries for capital gain. The narrative economy can be thought of as the trade of stories which ascribe value to assets for which other forms of capital (such as money and status) can be exchanged.

The primary actors in the narrative economy of the nascent Western Australian truffle industry include farmers and consumers. An important aspect of the narrative economy is the strategic construction of marketing narratives by farmers through social media to stimulate the generation of capital. The experience of Western Australian truffle farmers supports José van Dijck's (2013) theory that connectivity is staked on neoliberal economic principles. The market demands that farmers engage and compete through social media in order to sustain and develop their respective economic, social, and symbolic capital. Social media are influential platforms through which truffle growers seek recognition and endorsement from consumers in order to sustain and develop capital.

Farmers are learning that they can build capital by developing direct market engagement through social media; however, the degree of success is dependent on farmers' existing cultural capital in terms of communications know-how. They are also discovering some previously unencountered risks: consumers may use social media to publically challenge the values advance in industry narratives. A narrative economy can be seen not only as the construction of agenda-driven stories from producers to consumers, but also as a system of negotiation between producers and consumers.

Social media are fields in which truffle growers vie for advantageous positions relative to market rivals through direct engagement with consumers. But doing so requires them to develop narratives that enhance capital gain while mitigating risk. This supports James Carviou's (2014) argument that social media are not only fields through which narratives are projected, but also contested: 
'These sites are created for a specific purpose, but consumers can give them additional life by defining their meaning beyond the code' (Carviou 2014, 259).

Arjun Appadurai's (1990) notion of 'mediascapes' has converged with his related concepts of 'technoscapes' and 'financescapes' in new ways: farmers who have the economic and cultural capital to purchase communications hardware and use social media are able to compete for a market position in ways that other farmers, without those forms of capital, cannot. This challenges Appadurai's (1990) argument that advertising media renders consumers to be, at best, 'choosers'. Consumers may respond to grower narratives on social media with their own interpretations that undermine the capital values of producers and their narratives.

The mediated engagement of truffle markets also supports Pierre Bourdieu's (2002, 2007) argument that fields are spaces in which competition centres on the acquisition of capital. The genre of competition hosted by social media is commercial narrative. But rather than being a one-way deliverance of advertising from producer to consumer, the dynamic facilitated by social media is multi-directional. Consumers may convey their narratives to producers and between themselves - sometimes in defiance of the aims intended by growers. In this way, consumer narratives may be seen as adding and negating value to growers' narratives, and to other forms of capital such as reputation.

Truffle farmers' cultural capital must be developed to maintain these new ways of operation. Those who choose not to engage in narrative exchange with consumers through social media may lose symbolic capital (and ensuing social and economic capital). While growers can aim to develop capital on global markets 24 hours per day through social media, this also exposes them to risk. Consumers may be reinterpreting growers' narratives in ways not favourable to capital growth.

In recognising the variable agency of producers afforded by social media, it is important not to overstate how much power consumers have. Consumers may contest farmers' narratives, but farmers may still control the forms of engagement available to consumers - choosing types of social media which enable them to edit, remove or keep private those consumer narratives which reduce capital values, while promoting those that add value. Paradoxically, knowing how to do so requires more cultural capital in terms of a farmers' social media know-how.

José van Dijck (2013, 171-176) sees the decision of professionals not to develop social media presence as posing risks (in terms of reducing an actor's capacity to generate capital). But actors may not see themselves as 'laggards' (Rogers 2003) or 'victims' (Klein 2004). Farmers who choose not to engage through social media see their defiance as a form of empowerment. The development of the SFFC, and its use of social media by professional marketing teams (that are rich in cultural capital), enables more democratic distribution of symbolic capital to all of the region's farmers. Further, the SFFC facilitates marketing and social media training for all members, further investing in the cultural capital for all members. The SFFC and its regional brand serve to redistribute capital more equitably among producers. To this extent, social media facilitates the SFFC's attempts to democratise market engagement in ways envisaged by Nick Couldry (2015). Growers have a shared team of communications and marketing professionals whose cultural capital is used to stimulate growers' collective economic, social and symbolic capital. 


\section{Conclusion}

Social media and narrative economies require complex understandings in their own rights. This paper has only briefly explored the possibilities of considering each in relation to the other. However, it suggests that social theories on narrative economy may be developed in consideration of how they are formulated through social media, as fields through which actors negotiate values attributable to capital. Social media facilitates direct and multidirectional engagement between market actors from many different positions: between producers and consumers, consumers and consumers, and with professional and nonprofessional marketers. There are opportunities and risks for farmers in this form of engagement, and there is some degree of agency available to consumers - although this too may be mediated by industry.

Online forums are fields through which people with greater access to modes of communication can assert, and potentially leverage, greater economic and symbolic capital for themselves through and over others. But narratives may not deliver the effect desired by narrators. Consumers may interpret narratives differently from, and challenge the ways intended by, industry actors. Farmers attribute considerable power to consumers in social media fields; and they are cautious not to expose themselves, and their narratives, to unnecessary risk. Consequently, some farmers engage in market development through online narratives while others do not. The uneven distribution of symbolic and economic capital that ensues may lead to discord between farmers, and communities, as established power bases are renegotiated. However democratic institutions may have roles to play in developing social media in ways that distribute capital more consistently. The role of social media as a field of narrative exchange between producers and consumers deserves greater scholarly attention. A re-consideration of the multiplicity of forms narrative economies can take in social media might help theorists keep pace with the rapid convergence of neoliberal capitalism and social media.

\section{References}

Appadurai, A. (1990) 'Disjuncture and Difference in the Global Cultural Economy', Popular Culture, 2(2), 1-24

Bourdieu, P. (2002) 'The Forms of Capital'. In N.W. Biggard (ed) Readings in Economic Sociology. Malden, Massachusetts: Blackwell Publishers. pp. 280-291

Bourdieu, P. (2007) [1979] Distinction: A Social Critique of the Judgement of Taste. Translated by R. Nice. New York: Routledge

boyd, d. d., \& Ellison, N. B. (2007) 'Social Network Sites: Definition, History, and Scholarship', Journal of Computer-Mediated Communication, 13(1), 210-230

Brandão, A., \& Lira de Sousa, R (2015) 'The Performative Force of Bodies: Affective Realism in Contemporary Brazilian Cinema', Ilha Do Desterro: A Journal of English Language, Literature in English and Cultural Studies, 68(3), 161-170

Carviou, J. (2014) 'Book Review', Journal of Communication Inquiry, 38(3), 259-262

Couldry, N. (2015) 'lllusions of Immediacy: Rediscovering Hall's Early Work on Media', Media, Culture \& Society, 37(4), 637-644 
De Andrade e Silva, S. (2014) 'Review of "The Culture of Connectivity: A Critical History of Social Media"'. First Monday 19(4) [online], 7 April. Available at http://jouranls.uic.edu/ojs/index.php/fm/article/view/4571/3876. Accessed 15 October 2015.

De Solier, S. (2013) Food and the Self: Consumption, Production and Material Culture. London: Bloomsbury Academic

Hoskins, G. (2010) 'A Secret Reservoir of Values: The Narrative Economy of Angel Island Immigration Station', Cultural Geographies, 17(2), 259-275

Hoxter, J. (2011) Write What You Don't Know: An Accessible Manual for Screenwriters. New York: Continuum Publishing Group

Klein, J. (2004) 'Technology Laggards: Deviants or Victims?' Paper presented to Critical Management Studies Conference, University of Cambridge, [online], 4-6 July 2005. Available at http://www.mngt.waikato.ac.nz/ejrot/cmsconference/2005/proceedings/technology/ Klein.pdf. Accessed 30 May 2015.

Lewis, T. (2011) 'You've Put Yourselves on a Plate': The Labours of Selfhood on MasterChef Australia', in B. Skeggs and H. Wood (eds), Reality Television and Class, London: Palgrave-Macmillan, pp. 104-166

Mathews, A. (2013) 'Western Australia Black Truffles - Industry Snapshot', [online]. Available at https://www.agric.wa.gov.au/western-australian-black-truffles\%E2\%80\%93-industry-snapshot. Accessed 25 May 2015.

Mathews, A. (2014) 'Production of Cultivated Truffles in Western Australia'. [online] Available at https://www.agric.wa.gov.au/new-horticulture-crops/productioncultivated-truffles-western-australia. Accessed 25 May 2015.

Modesto, G-C., Savage, M. \& Warde, A. (2006) 'A Cultural Map of the United Kingdom, 2003'. Cultural Trends, 15(2-3), 213-237

Morley, N. (2006) 'Narrative Economy', in P. F. Bang, M. Inkegushi and H. G. Ziche (eds), Ancient Economies, Modern Methodologies: Archaeology, Comparative History, Models and Institutions, Bari: Edipuglia, pp. 27-47

Phillipov, M. (2012) 'Communicating Health Risks via the Media: What Can We Learn from “MasterChef Australia”?', Australasian Medical Journal, 5(11), 593-597

Rogers, E. M. (2003) [1962] Diffusion of Innovations. Fifth Edition. New York: Free Press

Scott, D. (2004) Conscripts of Modernity: The Tragedy of Colonial Enlightenment. London: Duke University Press

Southern Forests Food Council 2014 'Genuinely Southern Forests: The Council', [online]. Available at http://www.southernforestsfood.com/. Accessed 16 October 2014. 
Truffle Producers of Western Australia 2014 'The Truffe: Newsletter of The Truffle Producers Association of Western Australia', Issue 1, [online], June 2014. Available at http://truffleproducers.org.au/wp-content/uploads/2014/07/TheTruffe.pdf. Accessed 29 May 2015.

van Dijck, José (2013) The Culture of Connectivity: A Critical History Of Social Media Oxford: Oxford University Press

White, Smith \& Co. Publishers (2013) [1882] 'Das Spitzentuch der Königin', [online]. Available at http://imslp.org/wiki/Das_Spitzentuch_der_K\%C3\%B6nigin_\%28Strauss_Jr.,_Joh ann\%29. Accessed 8 December 2014.

World Wide Web Foundation (2015) 'History of the Web', [online]. Available at http://webfoundation.org/about/vision/history-of-the-web/. Accessed 30 May 2015.

Adele Millard is a PhD Candidate in the Discipline of Anthropology \& Sociology at The University of Western Australia.

Email: adele.millard@research.uwa.edu.au 